\title{
Pancreatic acinar cell carcinoma presenting with panniculitis, successfully treated with FOLFIRINOX: A case report
}

\author{
TOMOYASU YOSHIHIRO ${ }^{1}$, KENTA NIO ${ }^{1}$, KENJI TSUCHIHASHI ${ }^{1}$, HIROSHI ARIYAMA ${ }^{1}$, \\ KENICHI KOHASHI ${ }^{2}$, NOBUHIRO TSURUTA ${ }^{1}$, FUMIYASU HANAMURA ${ }^{1}$, KYOKO INADOMI ${ }^{1}$, \\ MAMORU ITO $^{1}$, KOSUKE SAGARA ${ }^{1}$, YUTA OKUMURA ${ }^{1}$, MICHITAKA NAKANO ${ }^{1}$, SHUJI ARITA ${ }^{3}$, \\ HITOSHI KUSABA $^{1}$, YOSHINAO ODA ${ }^{2}$, KOICHI AKASHI ${ }^{1}$ and EISHI BABA ${ }^{3}$ \\ ${ }^{1}$ Department of Hematology and Oncology, Kyushu University Hospital; ${ }^{2}$ Department of Anatomical \\ Pathology, Pathological Sciences, Graduate School of Medical Sciences; ${ }^{3}$ Department of Comprehensive \\ Clinical Oncology, Faculty of Medical Sciences, Kyushu University, Fukuoka 812-8582, Japan
}

Received November 3, 2016; Accepted March 29, 2017

DOI: $10.3892 /$ mco.2017.1240

\begin{abstract}
Pancreatic acinar cell carcinoma (PACC) is a rare tumor of the exocrine pancreas, representing only $1 \%$ of all pancreatic malignancies. A 50-year-old man presented with edema of the thumb joints bilaterally, followed by an appearance of masses in the bilateral lower extremities and fever $\left(38^{\circ} \mathrm{C}\right)$. The masses were diagnosed as panniculitis by skin biopsy, and multiple intraperitoneal masses were incidentally detected on pelvic magnetic resonance imaging performed to investigate the leg abnormalities. The patient was referred to the Kyushu University Hospital for further investigation, and fluorodeoxyglucose-positron emission tomography/computed tomography (CT) revealed high-uptake tumors in the pancreatic tail, in the periphery of the liver, and in the pelvis. Laboratory examinations revealed high serum concentrations of pancreatic exocrine enzymes, such as lipase, trypsin, elastase 1 and pancreatic phospholipase A2. Histological examination of a bioptic specimen obtained from a hepatic lesion revealed proliferation of atypical cells arranged in a tubular or glandular pattern. Immunohistochemical staining revealed that the atypical cells were positive for cytokeratin (CK)7, CK19 and lipase, but negative for CK20 and thyroid transcription factor-1, leading to a final diagnosis of acinar cell carcinoma of the pancreatic tail (T4bNOM1, stage IV according to the 7th edition of the TNM Classification of Malignant Tumors). Combined chemotherapy with oxaliplatin, irinotecan and fluorouracil (FOLFIRINOX) was administered and fever was soon alleviated. The serum levels of lipase also
\end{abstract}

Correspondence to: Professor Eishi Baba, Department of Comprehensive Clinical Oncology, Faculty of Medical Sciences, Kyushu University, 3-1-1 Maidashi, Higashi-ku, Fukuoka 812-8582, Japan

E-mail: e-baba@c-oncology.med.kyushu-u.ac.jp

Key words: pancreatic acinar cell carcinoma, lipase hypersecretion syndrome, pancreatic panniculitis, chemotherapy, FOLFIRINOX declined and panniculitis completely resolved. As of the start of the 8th course of chemotherapy, the levels of the pancreatic exocrine enzymes were within normal ranges and $\mathrm{CT}$ revealed partial response. Therefore, the severe lipase hypersecretion syndrome was well controlled by the FOLFIRINOX regimen and shrinkage of the mass was also achieved. Thus, the FOLFIRINOX regimen may represent an effective treatment option for advanced PACC.

\section{Introduction}

Pancreatic acinar cell carcinoma (PACC) is a rare tumor of the pancreas, comprising only $1 \%$ of all pancreatic malignancies (1). PACC usually presents with non-specific symptoms, such as abdominal pain and weight loss (2), but jaundice is less frequent compared with ductal carcinoma, as the tumor rarely arises in the head of the pancreas (3). The first report of PACC described by Berner was characterized by fever, polyarthritis, subcutaneous fat nodular necrosis and eosinophilia (4). These characteristics are collectively referred to as lipase hypersecretion syndrome (LHS), occurring due to lipase hypersecretion by PACC cells (5). Although PACC may be difficult to diagnose, subcutaneous fat necrosis, referred to as pancreatic panniculitis, may represent an initial symptom pointing to the diagnosis.

Despite the aggressive clinical behavior of PACC, its prognosis is more favorable compared with that of pancreatic ductal carcinoma, and surgical intervention is recommended if possible (6). However, LHS is more frequently encountered in patients with advanced disease, and its presence is considered to be a negative prognostic factor, along with a diameter of the primary tumor of $>10 \mathrm{~cm}$ and metastatic disease (7). In cases where curative resection is not applicable due to advanced disease, chemotherapy may be considered. Although no standard therapy for PACC has been established to date due to the rarity of this disease, 5-fluorouracil (5-FU) is considered to be more effective compared with gemcitabine (8).

We herein present the case of a patient who was diagnosed with PACC accompanied by LHS who responded well to treatment with the FOLFIRINOX regimen. 


\section{Case report}

In January 2016, a 50-year-old man consulted a dermatologist after developing edema of the thumb joints bilaterally, with subsequent appearance of masses in the bilateral lower extremities in February 2016. The patient had no significant past medical history, was a social drinker and had smoked until the age of 35 years. There were no reported allergies and no family history of malignant tumors. The physical examination revealed multiple subcutaneous masses in the lower extremities (Fig. 1), diagnosed as panniculitis by skin biopsy. To further examine these masses, pelvic magnetic resonance imaging (MRI) was performed and multiple intraperitoneal tumors were incidentally detected. As the patient had been suffering from a high fever since February, he was referred to the Kyushu University Hospital (Fukuoka, Japan) for further investigation.

On admission, the Eastern Cooperative Oncology Group (ECOG) performance status was 2 due to the persistent high fever. Physical examination revealed subcutaneous masses in the right chest wall and lower extremities. The blood test results were as follows: White blood cell count, 8,960/ $\mu 1$ (neutrophils, 91.4\%); and C-reactive protein, $9.43 \mathrm{mg} / \mathrm{dl}$. The liver function was mildly altered (aspartate aminotransferase, $80 \mathrm{U} / 1$; alanine aminotransferase, $229 \mathrm{U} / 1$; alkaline phosphatase, $872 \mathrm{U} / 1$; and $\gamma$-glutamyltransferase, $118 \mathrm{U} / 1$ ). Laboratory examination revealed high serum concentrations of pancreatic exocrine enzymes, such as lipase $(327,500 \mathrm{U} / \mathrm{l}$; normal range, $16-51 \mathrm{U} / \mathrm{l})$, trypsin $(68,400 \mathrm{ng} / \mathrm{ml}$; normal range, $100-550 \mathrm{ng} / \mathrm{ml}$ ), elastase 1 (3560 $\mathrm{ng} / \mathrm{dl}$; normal range, $<300 \mathrm{ng} / \mathrm{dl})$ and pancreatic phospholipase A2 (23,500 ng/dl; normal range, 130-400 ng/dl), but the amylase levels remained within the normal range $(111 \mathrm{U} / \mathrm{l})$. Pancreatic endocrine enzymes, such as C-peptide $(2.1 \mathrm{ng} / \mathrm{ml})$ and gastrin $(106 \mathrm{pg} / \mathrm{ml})$ were also within normal ranges. Tumor markers, such as $\alpha$-fetoprotein $(30.3 \mathrm{ng} / \mathrm{ml}$; normal range, $<6.2 \mathrm{ng} / \mathrm{ml}$ ), protein induced by vitamin $\mathrm{K}$ absence or antagonist-II $(87 \mathrm{mAU} / \mathrm{ml}$; normal range, $<40 \mathrm{mAU} / \mathrm{ml}$ ), and neuron-specific enolase $(17.9 \mathrm{ng} / \mathrm{ml}$; normal range, $<10 \mathrm{ng} / \mathrm{ml}$ ) were marginally elevated, but carcinoembryonic antigen $(0.9 \mathrm{ng} / \mathrm{ml})$, carbohydrate antigen (CA) 19-9 (34.7 U/ml), DUPAN-II (66 U/ml) and pro-gastrin-releasing peptide $(37.1 \mathrm{pg} / \mathrm{ml})$ were within normal ranges. Fluorodeoxyglucose-positron emission tomography/computed tomography (CT) revealed high-uptake mass lesions in the pancreatic tail, in the periphery of the liver and in the pelvis (Figs. 2 and 3). A transcutaneous biopsy of a liver lesion was conducted, and histological examination revealed proliferation of atypical cells arranged in a tubular or glandular pattern (Fig. 4A). Immunohistochemical staining showed that the atypical cells were positive for cytokeratin (CK)7, CK19 and lipase, but negative for CK20 and thyroid transcription factor-1 (Fig. 4B), which led to the final diagnosis of acinar cell carcinoma of the pancreatic tail, T4bNOM1, stage IV according to the 7th edition of the TNM Classification of Malignant Tumors (http://www.uicc.org/sites/main/files/ private/TNM_Classification_of_Malignant_Tumours_Website_15\% 20MAy2011.pdf).

While a fever of $38^{\circ} \mathrm{C}$ persisted, the results of the blood cultures were negative. It was concluded that the fever was caused by the tumor, and administered acetaminophen or non-steroidal anti-inflammatory agents only achieved temporary declines in fever. Chemotherapy with the FOLFIRINOX regimen (oxaliplatin at $85 \mathrm{mg} / \mathrm{m}^{2}$ on day 1, irinotecan at $180 \mathrm{mg} / \mathrm{m}^{2}$ on day 1,1 -leucovorin at $200 \mathrm{mg} / \mathrm{m}^{2}$ on day 1 , 5 -FU at $400 \mathrm{mg} / \mathrm{m}^{2}$ as a bolus infusion on day 1 , and 5 -FU at $2400 \mathrm{mg} / \mathrm{m}^{2}$ as a $46-\mathrm{h}$ continuous infusion, every 2 weeks) was initiated at the end of March, 2016. Alleviation of fever was soon achieved, the blood lipase levels also declined and panniculitis completely resolved over 7 seeks. The patient experienced no severe adverse events other than grade 1 malaise according to the Common Terminology Criteria for Adverse Events, version 4.0(https://evs.nci.nih.gov/ftp1/CTCAE/CTCAE_4.03_2010-06-14_ QuickReference_5x7.pdf) and the ECOG performance status became 0 . At the start of the 8th course of chemotherapy, the concentrations of pancreatic exocrine enzymes were within normal ranges and CT revealed partial response according to the Response Evaluation Criteria in Solid Tumors, version 1.1 (https://ctep.cancer.gov/protocoldevelopment/docs/recist_ guideline.pdf) (Fig. 4). The patient has been receiving FOLFIRINOX regimen for 12 months and maintained partial response at the last follow-up visit (March 30, 2017). The patient provided a signed informed consent regarding the publication of the case details and associated images.

\section{Discussion}

PACC originates from the acinar cells of the pancreas, the exocrine tissue in this organ. Although pancreatic tissue consists predominantly of acinar cells ( $82 \%$ by volume) (9), PACC represents only $1 \%$ of all pancreatic malignancies (1). PACC is morphologically and genetically distinct from common pancreatic ductal adenocarcinoma, and genetic alterations in the adenoma polyposis coli (APC)/ $\beta$-catenin pathway of PACC cells are often detected (10). Although the reason remains unclear, ductal adenocarcinoma has been hypothesized to arise from acinar cells via metaplasia to ductal cells, in a process known as acinar-ductal metaplasia (ADM) based on genetic instability (11). In fact, in transforming growth factor- $\alpha$ transgenic mice, an animal model for pancreatic cancer, acinar cells exhibited loss of their characteristic zymogen granules and became transitional cells, subsequently acquiring the characteristics of duct cells (12). In Kras ${ }^{\mathrm{G} 12 \mathrm{D}}$ transgenic mice, tumors predominantly originated not from ductal cells, but from acinar cells through ADM (13). These findings indicate that acinar cells represent the primary origin of pancreatic neoplasms.

Subcutaneous fat necrosis is most characteristic in PACC, but its pathogenesis has not been fully elucidated. One possible mechanism is that trypsin overproduced together with lipase alters the permeability of blood vessels, allowing lipase to hydrolyze lipids in the cell membrane and cytoplasm of adipocytes (14). LHS occurs in only $10-15 \%$ of patients with PACC and serum amylase activity is increased in only $30 \%$ of LHS cases (7). In the present case, amylase was the only pancreatic exocrine enzyme within the normal range.

Of the symptoms of LHS, subcutaneous fat necrosis referred to as pancreatic panniculitis is observed in $0.3-1 \%$ of all patients with pancreatic disease, such as acute and chronic pancreatitis and pancreatic neoplasms (15), and it is considered to be a dermadrome. 

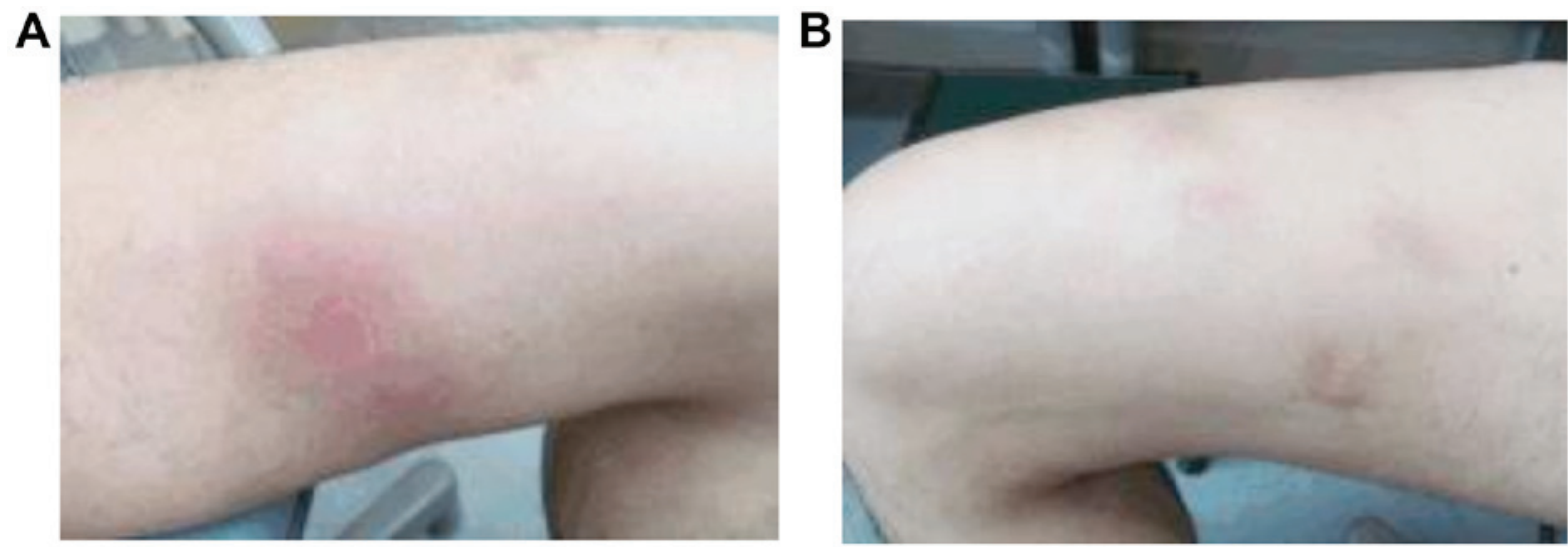

Figure 1. (A and B) Multiple subcutaneous masses were observed in the bilateral lower extremities.
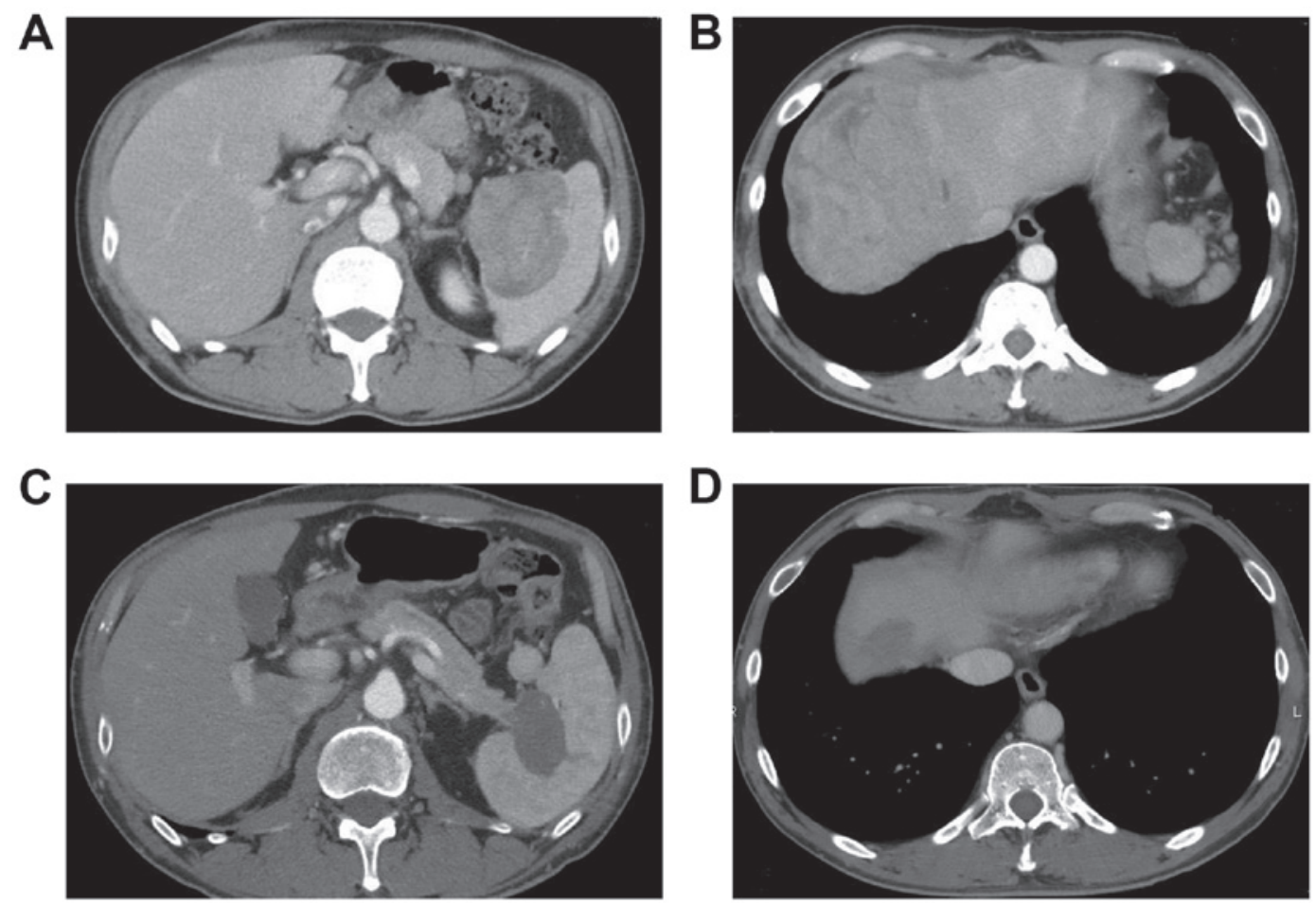

Figure 2. Computed tomography on admission revealed (A) a $65 x 55-\mathrm{mm}$ mass in the tail of the pancreas and (B) additional masses in the periphery of the liver. (C and D) Following administration of FOLFIRINOX, shrinkage of the masses was observed.

Patients with pancreatitis and those with neoplastic conditions tend to differ markedly, with tumor patients exhibiting significantly higher serum lipase concentrations. Retrospective analysis identified a serum lipase concentration of 4,414 U/1 as the optimal cut-off value, offering $73 \%$ sensitivity and $82.1 \%$ specificity for the diagnosis of a neoplastic cause (16). These sensitivity and specificity values are comparable with CA19-9 in ductal adenocarcinoma compared with benign pancreatic diseases (17). These findings suggest that patients with pancreatic panniculitis and high serum lipase concentrations should be carefully examined for neoplastic disease. Of the symptoms of LHS, severe fever and polyarthritis may worsen the general condition of the patient. Octreotide has been reported to alleviate the symptoms (16), but treatment directed at the underlying pancreatic disease is crucial.
Although no standard chemotherapy for advanced, unrespectable PACC has been established to date, some studies suggested a more favorable efficacy for 5-FU compare with gemcitabine (8). Considering the promising data for FOLFIRINOX against advanced pancreatic cancer (18), the present patient was treated with this regimen. Combination chemotherapy employing oxaliplatin or irinotecan for the treatment of colorectal cancer may be effective in PACC, as these tumors are associated with abnormalities in the APC/ $\beta$-catenin pathway, similar to colorectal carcinomas, and FOLFOX therapy has also been administered to PACC patients (19). In addition, sustained antitumor activity from oxaliplatin monotherapy was shown in basic research using a patient-derived tumor xenograft mouse model (20). In that model, irinotecan, gemcitabine and 5-FU also exhibited 

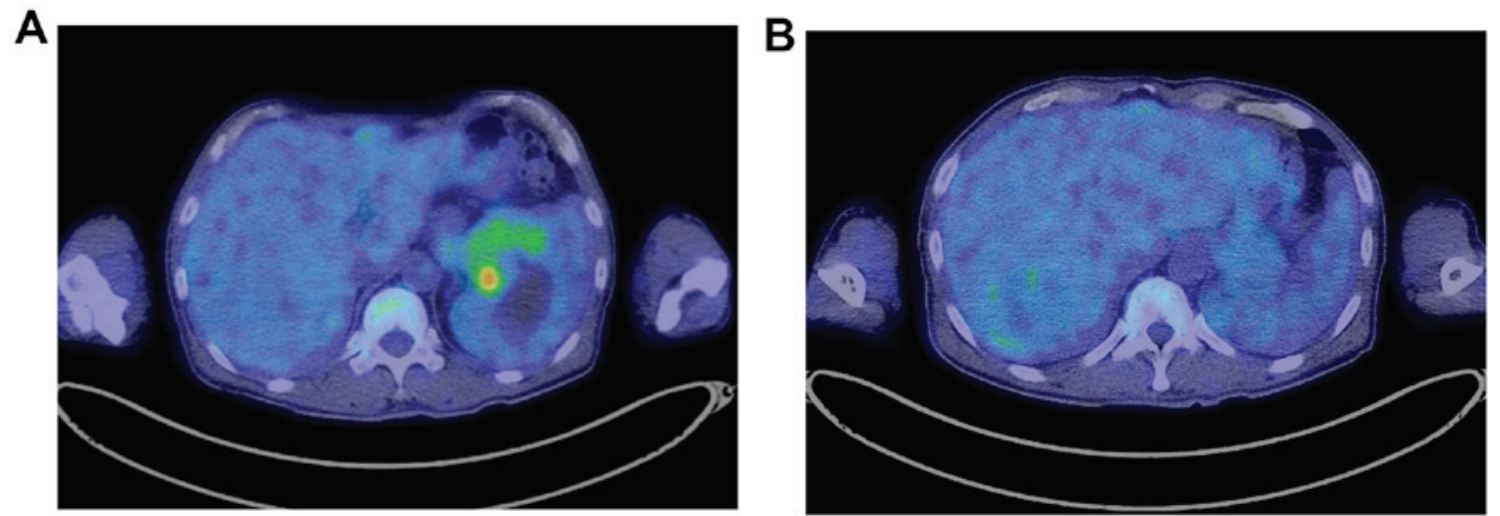

Figure 3. Fluorodeoxyglucose-positron emission tomography showing high-uptake lesions (A) in the pancreatic tail and (B) in the periphery of the liver.
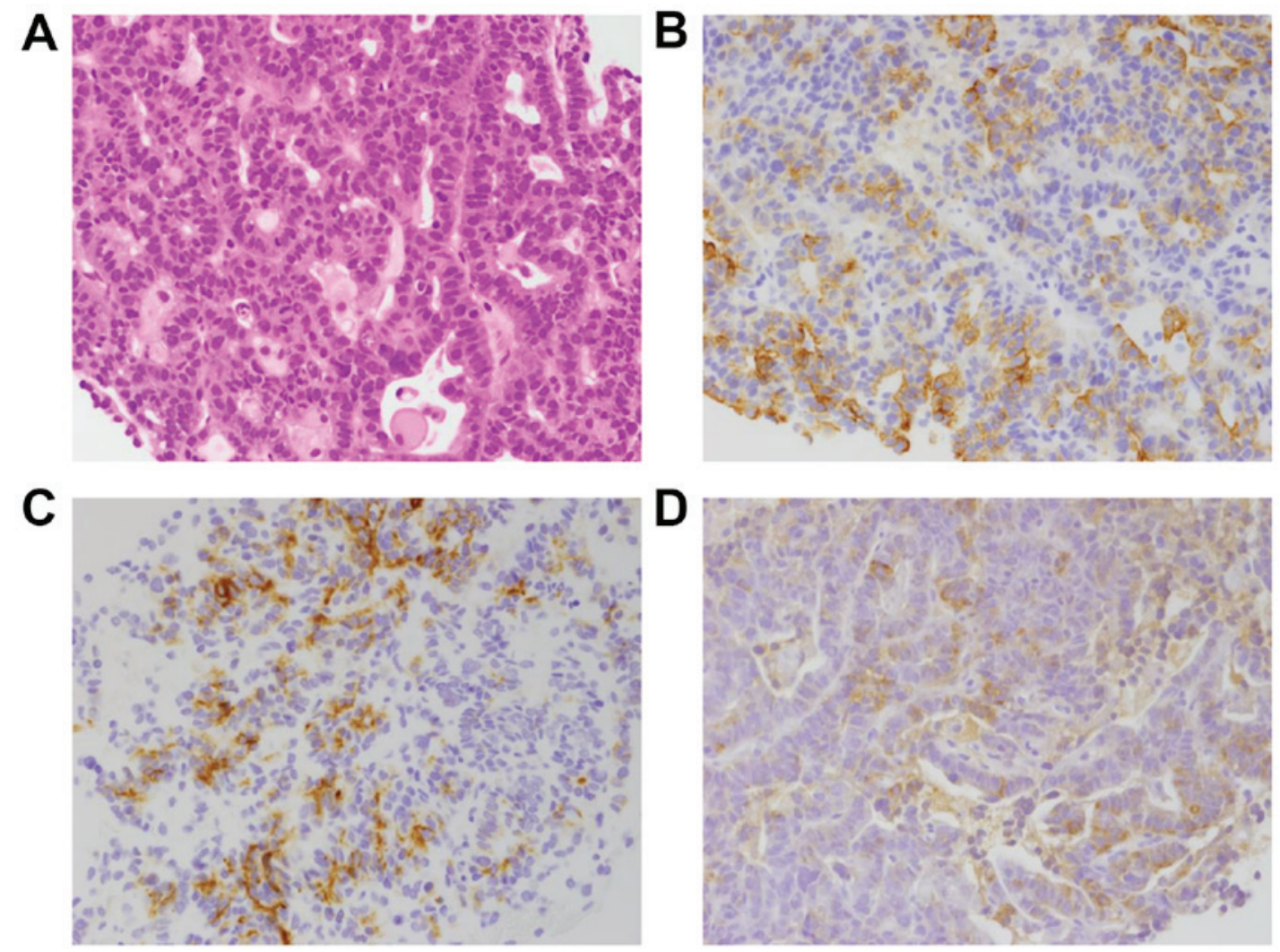

Figure 4. (A) Hematoxylin and eosin staining showing proliferation of atypical cells arranged in a tubular or glandular pattern. The atypical cells stained positive for (B) cytokeratin (CK)7, (C) CK19 and (D) lipase.

antitumor activity, but the tumor rapidly grew once those drugs were withdrawn. These findings suggested that oxaliplatin-based therapy may be one of the most effective therapies for the treatment of PACC.

In the PRODIGE 4/ACCORD 11 trial, FOLFIRINOX achieved significantly longer overall survival (OS) and progression-free survival (PFS) and a higher response rate compared with gemcitabine monotherapy (21). As the eligibility criteria for that study included a performance status of $0-1$, FOLFIRINOX is recommended for patients with a good general condition. In this case, the patient had a performance status of 2 due to a persistent fever of $38^{\circ} \mathrm{C}$ and polyarthritis. FOLFIRINOX was still administered, as the patient's condition was predicted to recover if symptom relief was achieved. Soon after treatment initiation, the symptoms induced by severe LHS were relieved and the performance status improved to 0 . This case suggests that administering chemotherapy to patients with poor performance status due to LHS should be considered, as symptom relief by chemotherapy is expected to lead to improvement of the performance status.

The patient presented herein was diagnosed with PACC overproducing exocrine enzymes, such as lipase. Severe LHS was well-controlled by FOLFIRINOX and shrinkage of the mass was also observed. To the best of our knowledge, this represents the first case in which FOLFIRINOX therapy achieved favorable control of advanced PACC with LHS, and 
chemotherapy should be considered as a viable option for those patients.

\section{Acknowledgements}

The authors would like to thank Dr Kazuko Imamura, Department of Dermatology, Fukuoka Saiseikai Futsukaichi Hospital, for providing pictures of the subcutaneous masses, as well as the medical staff of each institution who contributed to the treatment of the patient.

\section{References}

1. Holen KD, Klimstra DS, Hummer A, Gonen M, Conlon K, Brennan M and Saltz LB: Clinical characteristics and outcomes from an institutional series of acinar cell carcinoma of the pancreas and related tumors. J Clin Oncol 20: 4673-4678, 2002.

2. Butturini G, Pisano M, Scarpa A, D'Onofrio M, Auriemma A and Bassi C: Aggressive approach to acinar cell carcinoma of the pancreas: A single-institution experience and a literature review. Langenbecks Arch Surg 396: 363-369, 2011.

3. Klimstra DS, Heffess CS, Oertel JE and Rosai J: Acinar cell carcinoma of the pancreas. A clinicopathologic study of 28 cases. Am J Surg Pathol 16: 815-837, 1992.

4. Berner O: Subkutane fettgewebsnekrose. Virchow Arch Path Anat 193: 510-518, 1908 .

5. Wang Y, Wang S, Zhou X, Zhou H, Cui Y, Li Q and Zhang L: Acinar cell carcinoma: A report of 19 cases with a brief review of the literature. World J Surg Oncol 14: 172, 2016.

6. Schmidt CM, Matos JM, Bentrem DJ, Talamonti MS, Lillemoe KD and Bilimoria KY: Acinar cell carcinoma of the pancreas in the United States: Prognostic factors and comparison to ductal adenocarcinoma. J Gastrointest Surg 12: 2078-2086, 2008.

7. Riediger C, Mayr M, Berger H, Becker K, Dobritz M, Kleeff J and Friess H: Transarterial chemoembolization of liver metastases as symptomatic therapy of lipase hypersecretion syndrome. J Clin Oncol 30: e209-e212, 2012.

8. Simon M, Bioulac-Sage P, Trillaud H and Blanc JF: FOLFOX regimen in pancreatic acinar cell carcinoma: Case report and review of the literature. Acta Oncol 51: 403-405, 2012.

9. Williams JA: Regulation of acinar cell function in the pancreas. Curr Opin Gastroenterol 26: 478-483, 2010.

10. Abraham SC, Wu TT, Hruban RH, Lee JH, Yeo CJ, Conlon K, Brennan M, Cameron JL and Klimstra DS: Genetic and immunohistochemical analysis of pancreatic acinar cell carcinoma: Frequent allelic loss on chromosome $11 \mathrm{p}$ and alterations in the APC/beta-catenin pathway. Am J Pathol 160: 953-962, 2002.

11. Schmid RM: Acinar-to-ductal metaplasia in pancreatic cancer development. J Clin Invest 109: 1403-1404, 2002.

12. Wagner M, Greten FR, Weber CK, Koschnick S, Mattfeldt T, Deppert W, Kern H, Adler G and Schmid RM: A murine tumor progression model for pancreatic cancer recapitulating the genetic alterations of the human disease. Genes Dev 15: 286-293, 2001.
13. Kopp JL, von Figura G, Mayes E, Liu FF, Dubois CL, Morris JP IV, Pan FC, Akiyama H, Wright CV, Jensen K, et al: Identification of Sox9-dependent acinar-to-ductal reprogramming as the principal mechanism for initiation of pancreatic ductal adenocarcinoma. Cancer Cell 22: 737-750, 2012.

14. Vakiani E, Young RH, Carcangiu ML and Klimstra DS: Acinar cell carcinoma of the pancreas metastatic to the ovary: A report of 4 cases. Am J Surg Pathol 32: 1540-1545, 2008.

15. Bogart MM, Milliken MC, Patterson JW and Padgett JK: Pancreatic panniculitis associated with acinic cell adenocarcinoma: A case report and review of the literature. Cutis 80 : 289-294, 2007.

16. Zundler S, Erber R, Agaimy A, Hartmann A, Kiesewetter F, Strobel D, Neurath MF and Wildner D: Pancreatic panniculitis in a patient with pancreatic-type acinar cell carcinoma of the liver-case report and review of literature. BMC Cancer 16: 130, 2016.

17. Poruk KE, Gay DZ, Brown K, Mulvihill JD, Boucher KM, Scaife CL, Firpo MA and Mulvihill SJ: The clinical utility of CA 19-9 in pancreatic adenocarcinoma: Diagnostic and prognostic updates. Curr Mol Med 13: 340-351, 2013.

18. Callata-Carhuapoma HR, Pato Cour E, Garcia-Paredes B, Fernandez RM, Mendoza Fernandez ML, Fernandez AM, De La Rosa CA, Sotelo Lezama MJ, Cabezas-Camarero S and Sastre Varela J: Pancreatic acinar cell carcinoma with bilateral ovarian metastases, panniculitis and polyarthritis treated with FOLFIRINOX chemotherapy regimen. A case report and review of the literature. Pancreatology 15: 440-444, 2015.

19. Chaudhary P, Ranjan G, Chaudhary A, Tiwari AK and Arora MP: Acinar cell carcinoma: A rare pancreatic malignancy. Clin Pract 3: e18, 2013.

20. Hall JC, Marlow LA, Mathias AC, Dawson LK, Durham WF, Meshaw KA, Mullin RJ, Synnott AJ, Small DL, Krishna M, et al: Novel patient-derived xenograft mouse model for pancreatic acinar cell carcinoma demonstrates single agent activity of oxaliplatin. J Transl Med 14: 129, 2016.

21. Conroy T, Desseigne F, Ychou M, Bouché O, Guimbaud R, Bécouarn Y, Adenis A, Raoul JL, Gourgou-Bourgade S, de la Fouchardière $\mathrm{C}$, et al: FOLFIRINOX versus gemcitabine for metastatic pancreatic cancer. N Engl J Med 364: 1817-1825, 2011. 